\title{
Enhanced Anti-inflammatory Effects of $\gamma$-irradiated Pig Placenta Extracts
}

\author{
Kang Chang $\mathrm{Kim}^{\dagger}$, Jae Hyeok $\mathrm{Heo}^{\dagger}$, Jong Kwang Yoon, Yuyeon Jang, Youn Kyu Kim${ }^{1}$, \\ Chang-Kyu Kim², Yu-Kyung $\mathrm{Oh}^{3}$, and Young Bong Kim* \\ Department of Bio-industrial Technologies, College of Animal Bioscience and Technology, \\ Konkuk University, Seoul 143-701, Korea \\ ${ }^{1}$ KRIBS Co. Ltd, Jeomdong-myeon, Yeoju 469-870, Korea \\ ${ }^{2}$ Division of Animal Resources and Life Science, Sangji University, Wonju 220-702, Korea \\ ${ }^{3}$ College of Pharmacy and Research Institute of Pharmaceutical Sciences, \\ Seoul National University, Seoul 151-742, Korea
}

\begin{abstract}
Porcine placenta extract (PPE) is known to possess anti-inflammatory properties owing to its high concentration of bioactive substances. However, the need to eliminate blood-borne infectious agents while maintaining biological efficacy raises concerns about the optimal method for sterilizing PPE. Therefore, the objective of this study was to compare the effects of the standard pressurized heat (autoclaving) method of sterilization with $\gamma$-irradiation on the anti-inflammatory effects of PPE. The anti-inflammatory actions of these two preparations of PPE were evaluated by measuring their inhibitory effects on the production of NO, the expression of iNOS protein, and the expression of iNOS, COX2, TNF- $\alpha$, IL-1 $\beta$, and IL-6 mRNA in lipopolysaccharide-stimulated RAW 264.7 cells. Compared with autoclaved PPE, $\gamma$-irradiated PPE showed significantly greater inhibition of NO production and iNOS protein expression, and produced a greater reduction in the expression of iNOS, COX2, TNF- $\alpha$, IL-1 $\beta$, and IL- 6 mRNA. These results provide evidence that the sterilization process is crucial in determining the biological activity of PPE, especially its anti-inflammatory activity. Collectively, our data suggest that $\gamma$-irradiated PPE acts at the transcriptional level to effectively and potently suppresses the production of NO and the expression of pro-inflammatory cytokines.
\end{abstract}

Keywords: porcine placenta, anti-inflammation, pro-inflammatory cytokine, gamma irradiation

Received April 1, 2014; Revised December 8, 2014; Accepted January 15, 2015

\section{Introduction}

A number of chemicals have been developed as antiinflammatory pharmaceutical agents. However, these drugs are associated with unwanted side effects, such as gastric bleeding, with long-term use. As an alternative, studies have explored the development of medicines based on natural products. Placenta extract possesses antioxidant activity (Shinde et al., 2006) and has been shown to remove hydroxyl radicals, superoxide radicals, and inhibit the production of nitric oxide (NO) (Rozanova et al., 2010). The various active components of placenta are known to exert anti-inflammatory effects (Jash et al., 2011;

\footnotetext{
${ }^{\dagger}$ These authors contributed equally to this work.

*Corresponding author: Young Bong Kim, College of Animal Bioscience and Technology, Konkuk University, Seoul 143-701, Korea. Tel: +82-2-450-4208, Fax: +82-2-455-4208, E-mail: kimera@konkuk.ac.kr
}

McLachlan et al., 1986; O'Keefe and Chiu, 1988; Togashi et al., 2002). However, the wide use of placenta extract per se is limited owing to the presence of blood, which can transmit blood-borne infectious agents.

To minimize safety concerns, researchers have studied several methods for sterilizing placenta extract. Among the various methods for eliminating bacteria or viruses, the application of high pressure and temperature-autoclavinghas been widely used because it offers the advantage of complete sterilization. However, the harsh conditions of autoclaving can also affect the biological activity of temperature-sensitive components of placenta extract. Moreover, the previous study has shown that treatment with homogenized PPE significantly improved the cell viability of $\mathrm{H}_{2} \mathrm{O}_{2}$ treated human keratinocyte $(\mathrm{HaCaT})$ cells, whereas heated PPE $\left(110^{\circ} \mathrm{C}\right.$ for $\left.5 \mathrm{~h}\right)$ treatment had no obvious effect (Choi et al., 2014). Thus, a milder method capable of killing microorganisms without disrupting the activity of temperature-sensitive components would be desirable. 
In this study, we tested how sterilization with the new method of $\gamma$-irradiation affected the anti-inflammatory properties of porcine placenta extract (PPE) compared with those of PPE prepared by conventional autoclaving. Here, we report that $\gamma$-irradiated PPE exerted more effective and potent anti-inflammatory effects compared with autoclaved PPE.

\section{Materials and Methods}

\section{Preparation of PPE}

Porcine placenta tissues $(500 \mathrm{~g})$ in $500 \mathrm{~mL}$ of phosphate buffered saline (PBS) were disrupted using a tissue homogenizer (Tissue Tearor; Biospec Products Inc., USA). Homogenized tissues were centrifuged for $15 \mathrm{~min}$ at $6,000 \mathrm{~g}$ and supernatants were lyophilized, yielding a powdered form of PPE. PPE was then sterilized by autoclaving for $15 \mathrm{~min}$ at $121^{\circ} \mathrm{C}$ under pressure (15 psi) or by $\gamma$-irradiation. The $\gamma$-irradiation of PPE was performed in air using isotope source of Cobalt $60^{\circ} \mathrm{C}$ at Greenpia technology Co. (Korea), and the absorbed dose for $\gamma$-irradiation of PPE was $25 \mathrm{kGy}$ at a dose rate of $1 \mathrm{kGy} / \mathrm{h}$.

\section{Cell culture}

Murine macrophage RAW 264.7 cells were obtained from the Korean Cell Line Bank (Korea). RAW 264.7 cells were cultured at $37^{\circ} \mathrm{C}$ in Dulbecco's modified Eagle medium (Gibco-BRL, USA) containing 10\% fetal bovine serum, and $1 \%$ penicillin and streptomycin.

\section{Determination of NO production}

Concentrations of NO in cell culture medium were quantified using Griess reagent, as described previously (Green et al., 1982). Briefly, RAW 264.7 cells were seeded onto 6-well plates at a density of $2.5 \times 10^{5}$ cells/well and treated with $0.1,0.5$, or $1.0 \mathrm{mg} / \mathrm{mL}$ of autoclaved or $\gamma$ irradiated PPE for $24 \mathrm{~h}$. The cells were then further treated with $2 \mu \mathrm{g} / \mathrm{mL}$ of lipopolysaccharide (LPS; Sigma, USA) for $24 \mathrm{~h}$. Cell culture medium $(100 \mu \mathrm{L})$ was mixed with the same volume of Griess Reagent (1\% sulfanilamide and $0.1 \%$ naphthylenediamine dihydrochloride in $2.5 \%$ phosphoric acid) and left at room temperature for $10 \mathrm{~min}$. Color development was measured spectrophotometrically at $540 \mathrm{~nm}$. The concentrations of NO in the medium were calculated by reference to a standard curve established using known concentrations of sodium nitrite.

\section{Western blot analysis}

RAW 264.7 cells pretreated with autoclaved or $\gamma$-irradi- ated PPE for $24 \mathrm{~h}$ were cultured for an additional $24 \mathrm{~h}$ in the presence of $2 \mu \mathrm{g} / \mathrm{mL}$ of LPS. Cells were washed twice with ice-cold PBS and incubated at $4^{\circ} \mathrm{C}$ for $30 \mathrm{~min}$ in lysis buffer (50 mM Tris-HCl [pH 7.5], $150 \mathrm{mM} \mathrm{NaCl,} \mathrm{1 \%} \mathrm{NP-}$ 40, $2 \mathrm{mM}$ ethylenediaminetetraacetic acid [EDTA], $1 \mathrm{mM}$ ethylene glycol tetraacetic acid [EGTA], $1 \mathrm{mM} \mathrm{NaVO}_{3}$, $10 \mathrm{mM}$ NaF, $1 \mathrm{mM}$ dithiothreitol, $1 \mathrm{mM}$ phenylmethylsulfonyl fluoride [PMSF], $25 \mu \mathrm{g} / \mathrm{mL}$ aprotinin, $25 \mu \mathrm{g} / \mathrm{mL}$ leupeptin). The lysed cells were centrifuged at $14,000 \mathrm{~g}$ for $10 \mathrm{~min}$, and the supernatant was stored at $-70^{\circ} \mathrm{C}$. The concentration of proteins in PPE was measured using the Bradford assay (Bradford, 1976). Samples, containing 50 $\mu \mathrm{g}$ of protein each, were electrophoresed on a $10 \%$ sodium dodecyl sulfate-polyacrylamide gel, and transferred to a nitrocellulose membrane. The membrane was incubated for $1 \mathrm{~h}$ in $5 \%$ nonfat dried milk to block non-specific protein binding. Next, the membrane was incubated overnight at $4{ }^{\circ} \mathrm{C}$ with a mouse anti-iNOS (inducible nitric oxide synthase) primary antibody (1:1,000; Calbiochem, USA) and then for $2 \mathrm{~h}$ with a peroxidase-conjugated goat antimouse IgG secondary antibody (1:5,000; Amersham Pharmacia Biotech, UK). iNOS expression was visualized using enhanced chemiluminescence (ECL) detection reagents (Thermo Scientific, Pierce Biotechnology, USA).

\section{Reverse transcription-polymerase chain reaction (RT-PCR)}

The expression levels of genes encoding pro-inflammatory proteins in RAW 264.7 cells treated with PPE and lipopolysaccharide were measured by RT-PCR. Total RNA was extracted from treated cells using an RNeasy mini kit (Qiagen, USA) according to manufacturer's protocol and stored at $-70^{\circ} \mathrm{C}$ until use. One microgram of total RNA was reverse transcribed using M-MuLV reverse transcriptase (Promega, USA), oligo-dT primer, $0.5 \mu \mathrm{M}$ dNTP, and $1 \mathrm{U}$ RNase inhibitor. The resulting cDNA was amplified by PCR using 30 cycles of $94^{\circ} \mathrm{C}$ for $45 \mathrm{~s}$ (denaturation), $55^{\circ} \mathrm{C}$ for $45 \mathrm{~s} \mathrm{(annealing),} \mathrm{and} 72^{\circ} \mathrm{C}$ for $60 \mathrm{~s}$ (extension). The sequences of primers for iNOS, COX2, IL-1 $\beta$, IL-6, and TNF- $\alpha$ are listed in Table 1. PCR products were electrophoresed on a $1.2 \%$ agarose gel and stained with ethidium bromide.

\section{Results}

Effect of sterilization process on PPE-mediated inhibition of NO production

RAW 264.7 cells were treated with PPE sterilized by autoclaving or $\gamma$-irradiation, with or without subsequent 


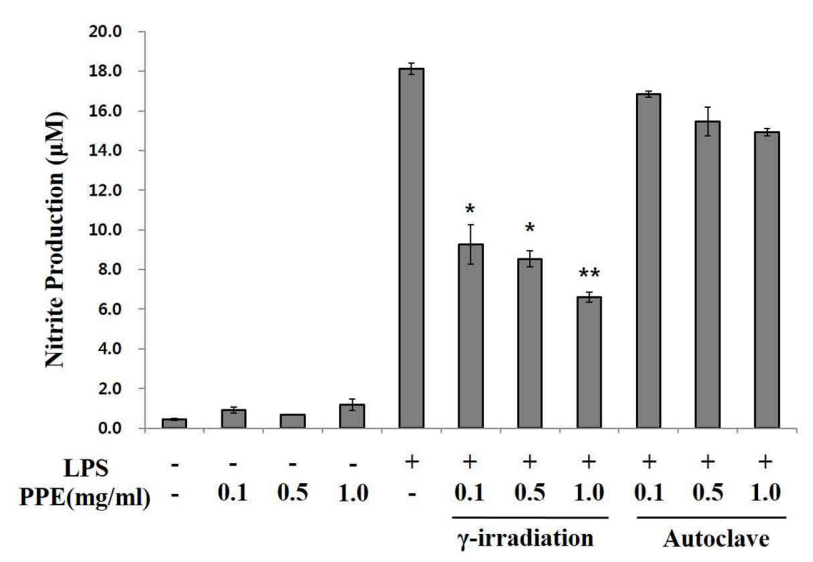

Fig. 1. Inhibitory effect of $\gamma$-irradiated and autoclaved PPE on NO production in LPS-stimulated RAW 264.7 cells. The production of NO in PPE-pretreated RAW 264.7 cells was assayed in the culture medium of cells stimulated with LPS $(2 \mu \mathrm{g} / \mathrm{mL})$ for $24 \mathrm{~h}$. Results are means \pm SEM of three independent experiments $\left({ }^{*} p<0.05,{ }^{* *} p<\right.$ 0.01 vs. LPS alone).

LPS stimulation. In the absence of LPS stimulation, PPE sterilized by either method had no effect on NO production in RAW 264.7 cells. PPE sterilized by either method retained the ability to inhibit NO production by LPSstimulated cells (Fig. 1). However, the efficacy of $\gamma$-irradiated PPE was greater than that of autoclaved PPE. In cells treated with autoclaved PPE, NO production was reduced to $19.2 \%$ only after treatment with a high dose of PPE $(1.0 \mathrm{mg} / \mathrm{mL})$. In contrast, $\gamma$-irradiated PPE decreased NO production by $50.2 \%, 54.3 \%$, and $65.2 \%$ at concentrations of $0.1,0.5$, and $1.0 \mathrm{mg} / \mathrm{mL}$, respectively.

Inhibition of iNOS expression in RAW 264.7 cells by $\gamma$-irradiated, but not autoclaved, PPE

Expression of iNOS in PPE-pretreated cells was measured at protein and mRNA levels by Western blotting and RT-PCR, respectively. In the absence of LPS stimulation, there was little expression of iNOS protein in RAW 264.7 cells; however, after stimulation with LPS, iNOS protein expression substantially increased. Autoclaved PPE did not decrease iNOS protein expression in LPS-stimulated cells. However, $\gamma$-irradiated PPE $(0.5$ and $1.0 \mathrm{mg} /$ $\mathrm{mL}$ ) significantly attenuated the induction of iNOS protein in RAW 264.7 cells (Fig. 2A), which was consistent with its inhibitory effect on NO production (Fig. 1). RAW 264.7 cells did not express iNOS mRNA in the absence of stimulation, but highly expressed iNOS mRNA upon stimulation with $2 \mu \mathrm{g} / \mathrm{mL}$ of LPS. Autoclaved PPE at a concentration of $1.0 \mathrm{mg} / \mathrm{mL}$ failed to attenuate LPS-
(A)

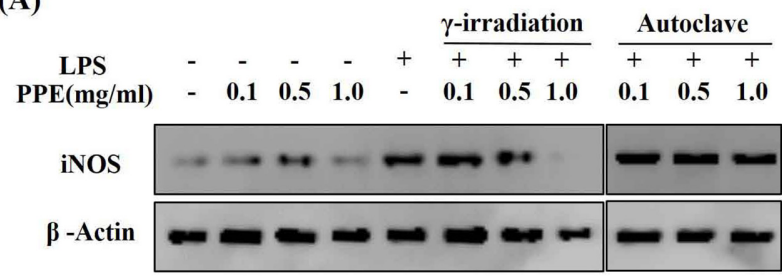

(B)

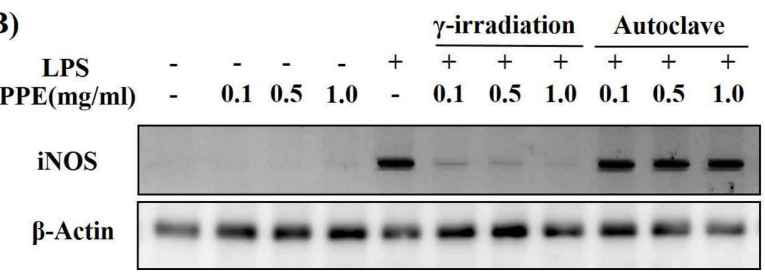

Fig. 2. Inhibitory effects of $\gamma$-irradiated and autoclaved PPE on iNOS protein (A) and mRNA (B) expression. RAW 264.7 cells $\left(2.5 \times 10^{5}\right.$ cells/well $)$ were pretreated with different concentrations of PPE for $24 \mathrm{~h}$, and further stimulated with LPS $(2 \mu \mathrm{g} / \mathrm{mL})$ for $24 \mathrm{~h}$. The levels of iNOS protein were determined by Western blotting. $\beta$-actin levels were used as a control.

induced increases in iNOS mRNA expression in RAW 264.7 cells. In contrast, this same concentration of $\gamma$-irradiated PPE inhibited LPS-induced iNOS mRNA expression in these cells; notably, $\gamma$-irradiated PPE was effective at $0.1 \mathrm{mg} / \mathrm{mL}$, the lowest concentration tested (Fig. 2B).

Inhibition of COX2 mRNA expression in RAW 264.7 cells by $\gamma$-irradiated, but not autoclaved, PPE

Inhibition of cyclooxygenase (COX)-2 is one of the known working mechanisms of anti-inflammatory drugs (Kim et al., 2010; Rocca and FitzGerald, 2002). We thus tested whether PPE sterilized by different methods exerted inhibitory effects on COX2. Stimulation of RAW 264.7 cells with LPS increased COX2 mRNA levels (Fig. 3). This increase in COX2 mRNA expression was not nearly decreased by pretreatment of cells with a high concentration $(1.0 \mathrm{mg} / \mathrm{mL})$ of autoclaved PPE. In contrast, pretreatment of RAW 264.7 cells with $\gamma$-irradiated PPE at a concentration of $0.1 \mathrm{mg} / \mathrm{mL}$ inhibited LPS-induced COX2 mRNA expression. Neither PPE preparation affected COX2 mRNA levels in unstimulated RAW 264.7 cells.

\section{Altered expression of mRNA for pro-inflammatory cytokines by pretreatment with PPE}

The pro-inflammatory cytokines tumor necrosis factor (TNF)- $\alpha$, interleukin (IL)- $1 \beta$ and IL-6, secreted by lymphocytes and macrophages, have been implicated in inflammation. Accordingly, we tested whether sterilization 


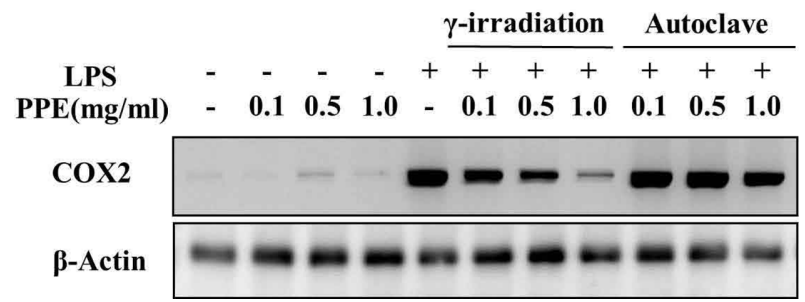

Fig. 3. Inhibitory effects of $\gamma$-irradiated and autoclaved PPE on COX2 mRNA expression. RAW 264.7 cells $\left(2.5 \times 10^{5}\right.$ cells/well) were pretreated with different concentrations of PPE for $24 \mathrm{~h}$, and further stimulated with LPS $(2 \mu \mathrm{g} /$ $\mathrm{mL}$ ) for $24 \mathrm{~h}$. $\beta$-Actin levels were used as a control.

method affected the ability of PPE to alter the expression of these pro-inflammatory cytokines, measuring the mRNA expression levels of pro-inflammatory cytokines by RTPCR using the primers shown in Table 1. Pretreatment of RAW 264.7 cells with $1.0 \mathrm{mg} / \mathrm{mL}$ of autoclaved PPE had little effect on LPS-induced TNF- $\alpha$ expression (Fig. 4). Unlike autoclaved PPE, $\gamma$-irradiated PPE inhibited LPSinduced TNF- $\alpha$ expression in concentration-dependent manner. LPS-induced IL-1 $\beta$ and IL- 6 expression were reduced by both autoclaved and $\gamma$-irradiated PPE (Fig. 4), although the potency of this inhibitory effect depended on the sterilization process. Pretreatment with autoclaved PPE inhibited the production of IL-6 in LPS-stimulated cells only at a high concentration $(1.0 \mathrm{mg} / \mathrm{mL})$. However, $\gamma$ irradiated PPE almost completely inhibited the production of IL-1 $\beta$ and IL-6 in LPS-stimulated cells at the lower concentration of $0.1 \mathrm{mg} / \mathrm{mL}$.

\section{Discussion}

This study demonstrated the importance of the sterilization process in the retention of PPE biological activity. We found that NO production, iNOS induction, and exp-

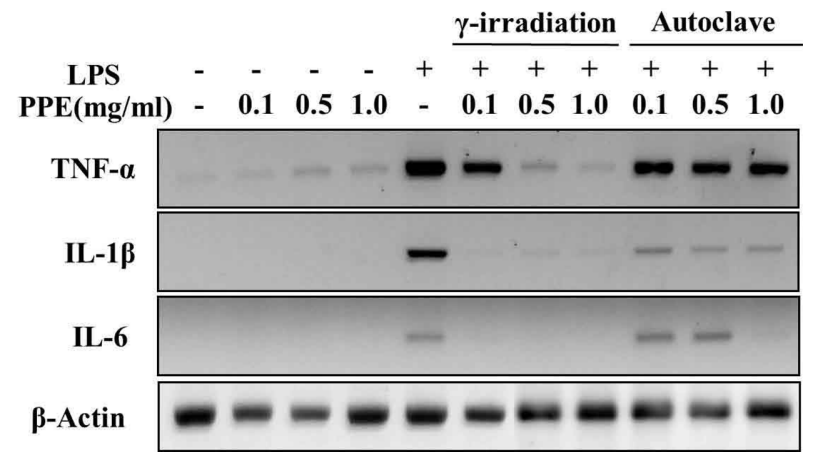

Fig. 4. Inhibitory effects of $\gamma$-irradiated and autoclaved PPE on pro-inflammatory cytokine mRNA expression. RAW 264.7 cells $\left(2.5 \times 10^{5}\right.$ cells/well $)$ were pretreated with different concentrations of PPE for $24 \mathrm{~h}$, and further stimulated with LPS $(2 \mu \mathrm{g} / \mathrm{mL})$ for $24 \mathrm{~h}$. $\beta$-Actin levels were used as a control.

ression of the pro-inflammatory cytokines TNF- $\alpha$, IL-1 $\beta$, and IL-6 in LPS-stimulated RAW264.7 cells was more effectively inhibited by pre-treatment with $\gamma$-irradiated PPE than with autoclaved PPE.

We observed that $\gamma$-irradiated PPE, but not autoclaved PPE, inhibited NO production by LPS-stimulated RAW 264.7 cells (Fig. 1). NO, an active oxygen species involved in the initiation of inflammatory reactions (Min et al., 2010; Weisz et al., 1996), is produced by NO synthase (NOS) during the biosynthesis of L-citrulline from L-arginine. There are three known NOS isoforms: endothelial NOS, neuronal NOS and iNOS (Kim et al., 2011). Of these, iNOS has specifically been implicated in inflammation and shown to be induced by stimulation with LPS or pro-inflammatory cytokines (Stuehr et al., 2010; Weisz et al., 1996). The inhibitory effect of $\gamma$-irradiated PPE on NO production in LPS-stimulated RAW 264.7 cells suggests that $\gamma$-irradiated PPE could inhibit iNOS transcription and/or translation. Consistent with this, we found that

Table 1. Primer sequences and fragment sizes in RT-PCR analyses of target genes

\begin{tabular}{|c|c|c|}
\hline Gene & Primer sequence & Size \\
\hline iNOS & $\begin{array}{l}\text { F: 5'-CCCTTCCGAAGTTTCTGGCAGCAGC-3' } \\
\text { R: 5'-GGCTGTCAGAGCCTCGTGGCTTTGG-3' }\end{array}$ & 496 \\
\hline $\mathrm{COX} 2$ & $\begin{array}{l}\text { F: 5'- CACTACATCCTGACCCACTT-3' } \\
\text { R: 5'- ATGCTCCTGCTTGAGTATGT-3' }\end{array}$ & 696 \\
\hline IL-1 $\beta$ & $\begin{array}{l}\text { F: 5'-CAGGATGAGGACATGAGCACC-3' } \\
\text { R: 5'-CTCTGCAGACTCAAACTCCAC-3' }\end{array}$ & 447 \\
\hline IL-6 & $\begin{array}{l}\text { F: 5'-GTACTCCAGAAGACCAGAGG-3', } \\
\text { R: 5'-TGCTGGTGACAACCACGGCC-3' }\end{array}$ & 308 \\
\hline TNF- $\alpha$ & $\begin{array}{l}\text { F: 5'-TTGACCTCAGCGCTGAGTTG-3' } \\
\text { R: 5'-CCTGTAGCCCACGTCGTAGC-3' }\end{array}$ & 364 \\
\hline$\beta$-Actin & $\begin{array}{l}\text { F 5'-GTGGGCCGCCCTAGGCACCAG-3', } \\
\text { R 5'-GGAGGAAGAGGATGCGGCAGT-3, }\end{array}$ & 603 \\
\hline
\end{tabular}


$\gamma$-irradiated PPE inhibited iNOS expression in these cells at both the mRNA and protein level (Fig. 2). These results support the conclusion that $\gamma$-irradiated PPE inhibits iNOS production in LPS-stimulated cells at the transcriptional, rather than the translational level. The mechanism by which $\gamma$-irradiated PPE inhibits iNOS transcription is not yet known and will require further investigation. As expected based on the results of NO production experiments, autoclaved PPE did not alter iNOS expression at the mRNA or protein level. These differences in the biological effects of autoclaved and $\gamma$-irradiated PPE underscore the importance of sterilization process in maximizing the efficacy of PPE.

In addition to iNOS, COX2 expression in LPS-stimulated RAW 264.7 cells was also suppressed by $\gamma$-irradiated PPE (Fig. 3). Like NO, prostaglandin E2 (PGE), which is produced from arachidonic acid via COX, is known to provoke inflammation. There are two COX isoforms, COX-1 and COX2; of these, COX2 plays a role in the inflammation (Choy et al., 2008; Murakami and Ohigashi, 2007). Currently available anti-inflammatory chemical agents act, at least in part, through suppression of PGE or COX2 production (Vane and Booting, 1995; Willoughby, 1988). The induction of COX2 in RAW 264.7 cells by LPS stimulation was suppressed by pretreatment with $\gamma$-irradiated, but not autoclaved, PPE. The inhibition of COX2 mRNA expression in cells pretreated with $\gamma$ irradiated PPE suggests that the PPE could act by suppressing COX2 transcription.

We further found that PPE differentially regulated the expression of the pro-inflammatory cytokines TNF- $\alpha$, IL$1 \beta$, and IL- 6 depending on the sterilization process (Fig. 4). Studies have shown that TNF- $\alpha$ mediates inflammation through stimulation of the acute phase reaction (Walsh et $a l ., 1991)$. IL-1 $\beta$ has been reported to play a role in inducing or sustaining inflammation (Largoet et al., 2003). IL6 is known to stimulate the release of inflammatory mediators, such as NO and PGE, as well as matrix metalloproteinases (Hernández-Díaz and García-Rodríguez, 2001). Importantly, IL-6, a pivotal pro-inflammatory cytokine, is known to mediate LPS-induced fever symptoms (Stein and Sutherland, 1998). The more potent suppression of these pro-inflammatory cytokines by pretreatment with $\gamma$ irradiated PPE highlights the importance of sterilization process for retention of PPE anti-inflammatory effects.

In conclusion, we report that the sterilization process is crucial for the biological efficacy of PPE, especially its anti-inflammatory actions. Our results suggest that $\gamma$-irradiated PPE acts at the transcriptional level to effectively and potently suppress the expression of $\mathrm{NO}$ and pro-inflammatory cytokines. Moreover, our results support the use of $\gamma$-irradiation as the method of choice for preparing PPE.

\section{Acknowledgements}

This work was supported by Business for Cooperative R\&D between Industry, Academy, and Research Institute funded Korea Small and Medium Business Administration (C0005915 and C0010962) in 2012.

\section{References}

1. Bradford, M. M. (1976) A rapid and sensitive method for the quantitation of microgram quantities of protein utilizing the principle of protein-dye binding. Anal. Biochem. 72, 248-254.

2. Choi, H. Y., Kim, S. W., Kim, B. W., Lee, H. N., Kim, S. J., Song, M., Kim, S., Kim, J., Kim, Y. B., Kim, J. H., and Cho, S. G. (2014) Alpha-fetoprotein, identified as a novel marker for the antioxidant effect of placental extract, exhibits synergistic antioxidant activity in the presence of estradiol. PLOS ONE 9, e99421.

3. Choy, C. S., Hu, C. M., Chiu, W. T., Lam, C. S., Ting, Y., Tsai, S. H., and Wang, T. C. (2008) Suppression of lipopolysaccharide-induced of inducible nitric oxide synthase and cyclooxygenase- 2 by Sanguis draconis, a dragon's blood resin, in RAW 264.7 cells. J. Ethnopharmacol. 115, 455-462.

4. Green, L. C., Wagner, D. A., Glogowski, J., Skipper, P. L., Wishnok, J. S., and Tannenbaum, S. R. (1982) Analysis of nitrate, nitrite, and $[15 \mathrm{~N}]$ nitrate in biological fluids. Anal. Biochem. 126, 131-138.

5. Hernández-Díaz, S. and García-Rodríguez, L. A. (2001) Epidemiological assessment of the safety of conventional nonsteroidal anti-inflammatory drugs. Am. J. Med. 110, 20S-27S.

6. Kim, D. H., An, B. J., Kim, S. G., Park, T. S., Park, G. H., and Son, J. H. (2011) Anti-inflammatory effect of Ligularia fischeri, Solidago virga-aurea and Aruncus dioicus complex extract in RAW 264.7 cells. J. Life Sci. 21, 648-683.

7. Kim, H. K., Lee, M. Y., Hong, I. P., Choi, Y. S., Kim, N. S., Lee, M. L., and Lee, S. C. (2010) Antioxidant and antimicrobial capacity of several monofloral honey correlation with phenolic and flavonoid contents. Korean J. Apiculture 25, 275282.

8. Largo, R., Alvarez-Soria, M. A., Díez-Ortego, I., Calvo, E., Sánchez-Pernaute, O., Egido, J., and Herrero-Beaumont, G. (2003) Glucosamine inhibits IL-1 $\beta$-induced NFKB activation in human osteoarthritic chondrocytes. Osteoarthritis Cartilage 11, 290-298.

9. McLachlan, R. I., Healy, D. L., Robertson, D. M., Burger, H. G., and de Kretser, D. M. (1986) The human placenta: A novel source of inhibin. Biochem. Biophys. Res. Commun. 140, 485-490.

10. Min, H. Y., Song, S. H., Lee, Kim, B. S., and Lee, S. K. (2010) 
Inhibition of lipopolysaccharide-induced nitric oxide production by antofine and its analogues in RAW 264.7 macrophage cells. Chem. Biodivers. 7, 409-414.

11. Murakami, A. and Ohigashi, H. (2007) Targeting NOX, INOS and COX-2 in inflammatory cells: Chemoprevention using food phytochemicals. Int. J. Cancer 121, 2357-2363.

12. O'Keefe, E. J. and Chiu, M. L. (1988) Stimulation of thymidine incorporation in keratinocytes by insulin, epidermal growth factor, and placental extract tract: Comparison with cell number to assess growth. J. Invest. Dermatol. 90, 2-7.

13. Rocca, B. and FitzGerald, G. A. (2002) Cyclooxygenases and prostaglandins: Shaping up the immune response. Int. Immunopharmacol. 2, 603-630.

14. Rozanova, S. L., Naumenko, E. I., Rozanova, E. D., and Nardid, O. A. (2010) Change of antioxidative properties of human placental extracts after freezing. Problems of Cryobiology 20, 288-297.

15. Shinde, V., Dhalwal, K., Paradkar, A.R., Mahadik, K. R., and Kadam, S. S. (2006) Evaluation of in vitro antioxidant activity of human placental extract. Pharmacology Online 3, 172179.

16. Stein, B. and Sutherland, M. K. (1998) IL-6 as a drug discovery target. Drug Discovery Today 3, 202-213.
17. Stuehr, D. J., Cho, H. J., Weon, N. S., Weise, M. F., and Nathan, C. F. (1991) Purification and characterization of the cytokine-induced macrophage nitric oxide synthase: An FADand FMN-containing flavoprotein. Proc. Natl. Acad. Sci. USA 88, 7773-7777.

18. Togashi, S., Takahashi, N., Iwama, M., Watanabe, S., Tamagawa, K., and Fukui, T. (2002) Antioxidative collagen derived peptides in human placenta extract. Placenta 23, 497-502.

19. Vane, J. and Booting, R. (1995) New insights into the mode of action of anti-inflammatory drugs. Inflamm. Res. 44, 1-10.

20. Walsh, L. J., Trinchieri, G., Waldorf, H. A., Whitaker, D., and Murphy, G. F. (1991) Human dermal mast cells contain and release tumor necrosis factor alpha, which induces endothelial leukocyte adhesion molecule 1. Proc. Natl. Acad. Sci. USA 88, 4220-4224.

21. Weisz, A., Cicatiello L., and Esumi, H. (1996) Regulation of the mouse inducible-type nitric oxide synthase gene promoter by interferon-gamma, bacterial lipopolysaccharide and NGmonomethyl-L-arginine. Biochem. J. 316, 209-215.

22. Willoughby, D. A. (1988) Effects of prostaglandins PGF2a and PGE1 on vascular permeability. J. Pathol. Bacteriol. 96, 381-387. 